\title{
Correction to: Safety and image quality of MR-conditional external fixators for 1.5 Tesla extremity MR
}

\author{
David H. Ballard ${ }^{1}$ - John D. Garrett ${ }^{2}$ - Alberto A. Simoncini ${ }^{2} \cdot$ Silvia Barbeito $^{2} \cdot$ Massimo "Max" Morandi $^{3}$ \\ Published online: 27 January 2021 \\ (C) American Society of Emergency Radiology 2021
}

Correction to: Emergency Radiology (2021) https://doi.org/10.1007/s10140-020-01880-4

In the original version of this paper contains an error in author name. Giovanni F. Solitro has been removed per author request. The Original article has been corrected.

Publisher's note Springer Nature remains neutral with regard to jurisdictional claims in published maps and institutional affiliations.

The online version of the original article can be found at https://doi.org/ $10.1007 / \mathrm{s} 10140-020-01880-4$

David H. Ballard

davidballard@wustl.edu

1 Mallinckrodt Institute of Radiology, Washington University School of Medicine, 510 S Kings Highway Blvd Campus Box 8131, St Louis, MO 63110, USA

2 Department of Radiology, LSUHSC-Shreveport, 1501 Kings Highway, Shreveport, LA 71103, USA

3 Department of Orthopaedic Surgery, LSUHSC-Shreveport, 1501 Kings Highway, Shreveport, LA 71103, USA 